\title{
SOBRE DIABOS, VIADOS E BICHAS PRETAS NA EDUCAÇÃO
}

\author{
(Dhttps://orcid.org/0000-0002-9932-5846 Florence Belladonna Travesti ${ }^{\text {A }}$ \\ (D) https://orcid.org/0000-0002-7809-5164 Jonas Alves da Silva Júnior ${ }^{\text {B }}$ \\ ${ }^{\text {A }}$ Universidade Federal Rural do Rio de Janeiro (UFRRJ), Nova Iguaçu, RJ, Brasil \\ ${ }^{\text {B }}$ Universidade Federal Rural do Rio de Janeiro (UFRRJ), Nova Iguaçu, RJ, Brasil \\ Recebido em: 04 nov. 2021 | Aceito em: 10 dez. 2021 \\ Correspondência: Florence Belladonna Travesti (travestif@gmail.com)
}

No meio de um fogo cruzado entre cis hetererossexuais e gays higienizados, a bicha se contorce para afirmar uma existência que não é nenhuma coisa nem outra.

"O diabo em forma de gente: [r]existências de gays afeminados, viados e bichas pretas na educação"

Megg Rayara Gomes de Oliveira

\section{Iniciando}

Publicado pela Editora Devires em 2020, o livro "O diabo em forma de gente: [r]existências de gays afeminados, viados e bichas pretas na educação", de autoria de Megg Rayara Gomes de Oliveira, é uma produção fruto da sua tese de doutorado em Educação, concluída em 2016, na Universidade Federal do Paraná.

Dividido em cinco capítulos, o livro aborda de maneira interseccional as categorias analíticas de educação, gênero, sexualidade, raça e classe, a partir da perspectiva de bichas pretas professoras e homens gays negros afeminados que, no exercício professoral na rede de ensino, enfrentam violências constantes, destacadamente a homofobia e o racismo, e que, frente a isso, repensam práticas educacionais para construir maneiras de resistência.

\section{Primeira travesti negra doutora do brasil}

Se até 2016 o Brasil afundava em uma desigualdade social/educacional nunca antes vista, porém extremamente sentida, em que não havia professora travesti negra doutora, a pesquisa de Megg Rayara Gomes de Oliveira supre uma lacuna de estudos que foi consolidada dentro dos estudos de gênero e educação, no qual até então imperava uma escassez acentuada em estudos interseccionais de gênero, classe e raça. 
O fato de Megg ser a primeira travesti negra doutora do Brasil já diz muito sobre o livro proveniente de sua tese, porque ao mesmo tempo em que nos dá adorno comemorativo pela quebra de uma barreira abissal (SANTOS, 2010), também nos acusa uma realidade dura de desigualdade que paira entre as travestis, que compõem um grupo social compulsoriamente marginalizado. O título de doutora de Megg, em uma população de aproximadamente 200 milhões de pessoas, em território nacional, imprime-nos uma noção basilar, cruel e extremamente transfóbica de como a sociedade marginaliza e mata em diferentes vias a população trans. Não garantir o direito básico à educação é uma destas maneiras.

\section{O diabo em forma de gente: [r] existências de gays afeminados, viados e bichas pretas na educação}

Mais especificamente, havia uma escassez acentuada de estudos envolvendo análises interseccionais entre pessoas LGBTI e raça, formando campos de estudos embranquecidos, e sutilmente racistas, em que o não diálogo entre gênero, sexualidade e raça passa facilmente despercebido por muitos que concentram estudos em uma única categoria de análise. Do mesmo modo, para a autora, também não é fácil fazer com que pesquisadores de relações étnico-raciais compreendam a necessidade de se estudar gênero.

É nesta encruzilhada que a pesquisa de Megg lança olhares, compreendendo que gênero, raça e classe são inevitavelmente híbridos, e a todo momento estão interligados enquanto categorias de subalternização.

Emergente de um saber localizado, chama-nos atenção a possibilidade de pensar numa academia masculina e embranquecida que negligencia não só existências dissidentes enquanto componentes ativos de ambientes universitários, mas também negligencia possibilidades de compreensão científica e de ensino escolar, formando ambientes educacionais ignorantes, que desqualificam determinadas existências e ciências provenientes daí.

Ao mesmo tempo, o livro privilegia a narrativa de resistência de professores gays afeminados, viados ou bichas pretas, como são identificadas em vias públicas pela cor da pele e pelo movimento corporal afeminado. Na perspectiva da autora, o que seria interpretado de maneira externa como uma ofensa, é ressignificado de modo que as próprias pessoas chamadas de "viado" e "bicha" reorganizam os discursos de estigmatização, tornando-as possibilidades de resistência pela subversão dos significados. É pensando nisso que a partir dos estudos interseccionais e da teoria foucaultiana dos dispositivos de poder, Megg começa de maneira didática a formular e entrelaçar a capitulação de seu livro. 


\section{Os dispositivos de controle que definem a categoria "raça"}

No exercício colonial em que o homem europeu se colocou como centro e referência universal, a construção da categoria de "raça", bem como as pessoas que a partir daí deveriam ser assinaladas, construiu, ao longo do tempo, uma materialidade grande e complexa dos processos de exclusão, a começar pelo modo como as próprias palavras são formuladas, forrando um campo de dominação inicialmente discursivo.

É aí que os vocábulos "negro/a" e "preto/a", mesmo construídos a partir de dicotomias que, de acordo com Megg, giravam em torno do desprezo do branco em relação às pessoas "de cor", não são, em suas origens, nomeações de caráter identitário, mas taxativo, demarcatório, estigmatizante. Ao mesmo tempo, foi a partir dessa construção discursiva ao longo do tempo, que tais adjetivos também se tornaram uma forma de resistência, de subversão do que seria um estigma para uma identidade, de uma luta histórica por reconhecimento e resistência de pessoas racializadas por seu pertencimento étnico.

Ao mesmo tempo, considerando o propósito do livro, as dissidências sexuais pontuam outro aspecto de marginalização para as bichas pretas que, destoantes dos padrões branco-cishetero-masculinos, não condizem com o esperado para pessoas nascidas com pênis. É nessa relação que emerge a questão que dará 'sul' ao estudo de Megg Rayara Gomes de Oliveira.

A bicha preta, que transita entre masculinidades e feminilidades, ao mesmo tempo que tem movimentos corporais afeminados, é perpassada pela hipersexualização despendida sobre homens negros cisgêneros e heterossexuais, dos quais, numa visão racista, espera-se um apetite sexual animalesco, desproporcional ao que é considerado humano, sendo extremamente viril e, principalmente, possuidor de um grande pênis, com proporções agigantadas, não humanas.

Nessa perspectiva, o processo de construção de uma homofobia branca-cisheterossexualmente compulsória frente aos gays afeminados, viados e bichas pretas formam um molde de exclusão envolto de biopoderes que atuam como um higienismo social, atuando massivamente em ambientes e situações que denotam tomadas de poder, sobretudo em profissões como a docência, invisibilizando e embranquecendo cada vez mais pessoas dissidentes em espaços de poder.

\section{"A bicha nasce do discurso"}

Em uma discussão teórica, Megg nos demonstra que o "esquecimento" de se discutir raça junto ao gênero não é um problema particular exclusivo aos estudos gênero focado em pessoas LGBTI, mas também aconteceu o mesmo nos estudos feministas de décadas e séculos 
passados, formando aí um padrão que comumente prefere não enxergar o racismo enquanto uma categoria de análise indissociável ao gênero. Foi assim que, no passado, o feminismo sufragista desconsiderou mulheres negras e, hoje, o feminismo mainstreaming pensa em gênero e classe a partir de mulheres brancas.

Não só no período colonial, mas tal relação está estabelecida porque os estudos gays, lésbicos, bissexuais e travestis estão intimamente ligados às diferentes corrente feministas, sobretudo, aqueles emergidos durante e depois dos anos 1960, considerando-se toda a carga contracultural que esse período histórico carrega em diferentes países e continentes, quando pontuado os movimentos antirracistas nos EUA, a liberação sexual na França, a descolonização de África e Ásia e as resistências aos governos ditatoriais na América do Sul.

Nesse ínterim entre raça e gênero, a bicha preta compõe sua própria referência de contracultura, não cedendo aos padrões de masculinidade e feminilidade vigentes, ou até, por vezes, usando-os de maneira estratégica em um exercício de resistência frente a determinados ambientes de poder, como um ataque aos padrões brancos-cis-heterossexuais.

Ao mesmo tempo, conta-nos Megg, que a bicha é uma fissura ao homossexual branco heteronormativo, isso nos faz pensar como essas fissuras identitárias são coagidas por processos que dialogam, em diferentes perspectivas, com o racismo, misoginia e LGBT Ifobia dentro de uma parte da comunidade LGBTI que, corrompida pelo preconceito, acaba por repelir pessoas que não seguem normas de comportamentos moralistas hegemônicos. Mesmo que essas normas hegemônicas nunca tenham como referência pessoas dissidentes. Ou seja, por mais que algumas pessoas dissidentes desejem a normalização; esta que incide sobre todos os corpos, em nossa sociedade, sempre identificará muito bem todas as diferenças.

Megg nos diz que o "gay e bicha são categorias diferentes. Expressam condutas diferentes. A bicha resiste. O gay se ajusta. Mas, se esse gay é afeminado, basta para que seja tratado como viado, como bicha. O ajuste não se efetiva" (OLIVEIRA, 2020, p. 109), dando uma noção de como os dispositivos de poder operam sobre esses corpos, constantemente vigiados, observados e passíveis de punição.

\section{Ser bicha preta professora: ensinar e aprender resistências}

Na parte final do livro, Megg Rayara faz uma pergunta central: "E se uma bicha tivesse infância, como seria?" (OLIVEIRA, 2020, p. 114). A autora privilegia um trânsito peculiar que passeia entre entrevistas feitas com bichas pretas professoras em suas vivências de gênero e sexualidade, ao mesmo tempo que, em determinados momentos, traz à tona suas próprias 
memórias de criança e adolescente negra em período escolar. É nessa contenda que os últimos dois capítulos do livro trazem uma força didática explícita reveladora de como o racismo e a homofobia interferem nos rumos de vida de determinadas crianças, com determinados corpos, em determinados ambientes sociais, com determinadas famílias e em determinadas escolas.

Numa perspectiva cis-heteronormalizadora, o corpo pequeno de uma criança negra toma outra proporção diante de corpos infantis brancos que compreendem o privilégio da raça branca em detrimento da raça negra, quando uma criança negra que não corresponde aos padrões de masculinidades vigentes em nossa sociedade é facilmente vigiada por adultos e outras crianças brancas que passam a tratá-la como má companhia ou sujeito suspeito.

Essa constante desconfiança de "algo errado" sobre as crianças negras dissidentes de gênero e sexualidade coloca sobre esse corpo uma pressão psicológica intensa e complexa que privatiza esse corpo da própria infância. Ou seja, crianças negras dissidentes de gênero e sexualidade, sejam meninos afeminados ou meninas masculinizadas, são tratadas como adultos desde cedo, ou pior, recaem sobre essas crianças, de forma escancarada, todo o racismo e homofobia que um adulto pode praticar com outro.

O que Megg Rayara constrói de maneira muito bem feita na parte final no livro, por meio de entrevistas com bichas pretas professoras, em nossa concepção, tem uma sacada dupla: ao passo que denuncia e possibilita a publicização das estratégias de subversão e resistência de bichas pretas professoras na atualidade, também traz à tona, por meio das entrevistas e do ato de memória, a voz das bichas pretas crianças, por muito tempo inaudíveis.

\section{Considerações finais}

O livro "O Diabo em forma de gente: [r]existências de gays afeminados, viados e bichas pretas na educação" consolida-se como obra fundamental para os estudos de gênero, raça, sexualidade e classe, suplementando uma feitura antirracista, e contra-pontuando estudos acadêmicos que não condizem com o meio social brasileiro. Isso porque qualquer pesquisa que não considere a categoria de raça enquanto importante vetor nos estudos acadêmicos, também desconsidera a realidade material de que o Brasil tem $56,2 \%$ da população autodeclarada preta e parda, de acordo com dados do IBGE ${ }^{\mathrm{i}}$.

Ao mesmo tempo, numa perspectiva acadêmica atual, Megg Rayara Gomes de Oliveira (2020) mantém um diálogo constante com epistemologias nacionais e internacionais, feitas por pessoas referências nos estudos de gênero, raça e classe, atualizando-nos das possibilidades teóricas que uma pesquisa antirracista e antiLGBTIfóbica pode ter. 
Por fim, de maneira muito mais delicada, acreditamos que por vieses das entrevistas contidas no estudo, assim como algumas memórias da autora, é possível entrever na obra um exercício acadêmico que abre espaço para bichas pretas professoras publicizarem suas vivências, resgatando, sutilmente, um pouco de voz das bichas pretas crianças; crianças essas que, por muito tempo, ao longo da história e de suas próprias histórias de vida, nunca foram ouvidas devidamente.

\section{Referências}

GOMES DE OLIVEIRA, Megg Rayara. O Diabo em forma de gente: [r]existências de gays afeminados, viados e bichas pretas na educação. $1^{\mathrm{a}}$ ed. Salvador - BA: Editora Devires, 2020.

SANTOS, Boaventura de Sousa. Para além do pensamento abissal: das linhas globais a uma ecologia de saberes. In: Paulo: Cortez, 2010. pp. 31-83. ; MENESES, Maria Paula (Org.). Epistemologias do Sul. São

\footnotetext{
i Disponível em https://educa.ibge.gov.br/jovens/conheca-o-brasil/populacao/18319-cor-ou-raca.html
} 